\title{
Decolonizing Engagement? Creating a Sense of Community Through Collaborative Filmmaking
}

\author{
SARAH MARIE WIEBE \\ University of Victoria, Canada
}

\begin{abstract}
The visual medium has the potential to be a creative avenue for enhancing awareness, critical thought and social justice. Through the prism of collaborative filmmaking, academic-activists can enrich textual analyses while creating what Jacques Rancière calls a "sense of community" among participants. This article reflects on the process of co-producing an Indigenous youth-driven documentary film, Indian Givers, which is publicly available on YouTube. It discusses the applied practice of engaging in a collaborative process with the aim of countering Western models of knowledge. The film and this article each draw into focus the experiences and stories of Indigenous youth who live in a highly polluted place commonly referred to as Canada's "Chemical Valley." Informed by Chantal Mouffe's notion of agonism, I contend that collaborative filmmaking contributes to anti-oppressive and community engaged scholarship by facilitating intercultural dialogue, offering a reflexive and relational approach to research, co-creating knowledge and contributing to social action. This paper reflects on some of the challenges of collaborative filmmaking in order to contribute to academic-activist research. As an anti-oppressive research tool, collaborative filmmaking provides a forum for resistance to dominant colonial discourses while creating space for radical difference in pursuit of decolonization.
\end{abstract}

KEYWORDS Indigenous peoples; community engaged scholarship; collaborative filmmaking; intercultural dialogue; environmental justice

Politics revolves around what is seen and what can be said about it, around who has the ability to see and the talent to speak, around the properties of spaces and the possibilities of time. (Rancière, 2004, p. 8)

Collaborative filmmaking is an artistic practice with the potential to help transform knowledge production and enhance dialogue. This type of artsbased intervention is often geared toward what Peter Nyers refers to as "radical equality" (2010, p. 131), where individuals speak and contribute to 
political life in unexpected ways. Indeed, as Jacques Rancière (2004, p.8) highlights, art can disrupt "the sensible," acting as an aesthetic intervention into the "general distribution of ways of doing and making" in order to create space for situated modes of being and forms of visibility.

In this article I argue that collaborative filmmaking can be used to create such a disruption, thereby providing an opportunity for community engaged scholarship. This form of scholarship draws upon principles of participatory action research (PAR), which include community relevance, equitable participation, action and change, and research design (Cahill, 2007; Ochocka \& Janzen, 2014; Pain, 2004; Wiebe \& Taylor, 2014). Community engaged scholarship can thus be viewed as an anti-oppressive, anti-hierarchical research approach that shifts power relations away from an authoritative expert. Reflecting on my experience co-producing Indian Givers, ${ }^{1}$ a documentary film created with Indigenous youth from the Aamjiwnaang First Nation community in Southwestern Ontario to address issues related to racism and ongoing environmental injustice, I contend that collaborative filmmaking can create a "sense of community" among its participants (Rancière, 2009, p. 26). By involving Indigenous youth as equal participants in the co-creation process, the film revealed knowledge about their everyday lives and experiences. In the discussion that follows, I examine some of the opportunities and challenges we encountered during the filmmaking process and conclude by suggesting that this creative methodology can be a useful and productive approach for academic-activists wanting to conduct collaborative research initiatives, particularly in the colonial present.

\section{Creating a Forum for Intercultural Dialogue}

I want to give an understanding of First Nations issues today, and talk about why everything is the way it is. To show that we aren't, you know, this extinct species of people. We're not just in museums and textbooks. We are actually living people today. (Jake Rogers, Indian Givers, 6:18)

Indian Givers is a 60-minute documentary film that is publicly available on YouTube. The film takes viewers on a journey through the eyes of young Indigenous people living on the Aamjiwnaang First Nation's traditional territory. It offers a glimpse into their ongoing struggles as they seek to

\footnotetext{
${ }^{1}$ To access Indian Givers, see https://www.youtube.com/watch?v=pot411GJzdM. Timestamps from the film are provided throughout the text (e.g., 6:18). 'Indian' is a term that appears in Canadian law, policy, and discourse and is charged with contested meaning. Its use in the film is in response to language from Canada's colonial Indian Act, which came into effect under Section 91(24) of the 1867 Constitution Act, and gave the federal government the exclusive authority to legislate in relation to "Indians and Land Reserved for Indians." Despite the explicit language in the Indian Act referring to Canada's Indian peoples, in this article I use the term Indigenous peoples, as the concept of the 'Indian' in Canada is an ill-informed colonial creation, which Indian Givers addresses.
} 
maintain a connection to their Indigenous identities in a now polluted landscape. The traditional lands of the Aamjiwnaang First Nation are occupied today by Canada's Chemical Valley, a heavy industrial complex located in Southwestern Ontario, and home to approximately 62 petrochemical and polymer facilities on both sides of the Canada-U.S. border. This situation affects the local atmosphere, water, and soil, as well as residents' health and wellness. It compromises both their physical and cultural survival, thus connecting issues of environmental and reproductive justice (Ecojustice, 2007; Hoover et al., 2012; Wiebe \& Konsmo, 2014; Wiebe, forthcoming). The film follows the narratives of three Indigenous youth as they fight for physical and cultural survival, and confront mainstream Canadian society while living in an environmentally stressed setting. Throughout the documentary, these three youth interview community members who discuss the realities of coping with everyday environmental assaults on their homes, bodies, and territories.

Accessing and bringing to light this experiential knowledge through an artistic medium can rupture oppression and open up space for alternative stories, experiences, and truths to emerge. Through this visual medium, young Indigenous people were able to challenge social exclusion and stereotypes by making their existence visible and knowable. The film gave voice to something they felt had been silenced. In doing so, Indian Givers emerged as a serious attempt to engage with Indigenous peoples, identities, and cultures - to highlight the meaning of Indigeneity, or being Indigenous today - in order to interrupt stereotypes and open up a forum for intercultural dialogue.

My definition of interculturalism is informed by Chantal Mouffe's (2005) notion of agonistic pluralism and inspired by Québec's Consultation Commission on Accommodation Practices Related to Cultural Diversity (Bouchard \& Taylor, 2008). From my view, intercultural dialogue moves beyond multicultural policies by cultivating conditions that allow for creative tensions in the spirit of respect for differences. In other words, interculturalism is a philosophical approach to difference that does not seek to eliminate differences while seeking a common identity. In practice, it entails an iterative dialogical process that creates space for exchange, negotiation, and dis/agreement rather than confrontation and division.

Informed by this approach, and based on the principles of community engaged scholarship, our collaborative film initiative in Aamjiwnaang aimed to both visualize and contextualize participants and their lived experiences. Similar to Rancière's claims about community theatre, collaborative filmmaking is a vehicle that has the potential to create a "sense of community" among participants who are involved in the process (2009, p. 16); it brings individual bodies together as a collective for which non-hierarchical relationship-building is crucial. Building relationships is central to actionoriented, intersectional, and Indigenous research, which explore and emphasize complexities, while acknowledging entanglements between 
researcher and researched, facilitator and participant (Banister, Leadbeater \& Marshall, 2011; Clover, 2011, 2014; Kindon, 2003; Kovach, 2009; Mullin, 2003; Thomas \& Britton, 2012, p. 212; Tuhiwai Smith, 1999). From this perspective, relationships matter more than results (Miller \& Smith, 2012, p. 332). Ethical relationship-building that is respectful of Indigenous ways of knowing can challenge mainstream Western forms of extractive knowledge production, which clearly delineate between 'the researcher' and 'researched.' From a collaborative approach, scholars must respect the agency of communities, which entails looking alongside the subject, issue, or context under examination, rather than "looking at" passive research participants (Kindon, 2003, p. 143). Collaborative film thus brings all involved members into the process and makes them co-producers.

\section{A Relational, Reflexive and Anti-Oppressive Approach}

Situating myself and questioning my inherited social and geopolitical context illuminates the vantage point I bring to this study. Awareness of social location - of the researcher's place - in relation to the research context is a crucial aspect of action-oriented, community engaged, intersectional scholarship (Hankivsky, 2012; Wiebe \& Taylor, 2014). Originally from the west coast of Canada, and raised just outside of Vancouver, B.C., on TsleilWaututh territory, I have always been passionate about social justice issues and the environment. As someone with mixed Western/European Settler ancestry, my training as a graduate student at the University of Victoria and the University of Ottawa instilled in me a way of thinking critically about settlement, ongoing conditions of colonization, and the significance of place to Indigenous ways of life. Understanding the lasting impact of colonization is critical to any conversation or research methodology oriented toward decolonization.

My doctoral studies took me from Canada's west coast to the nation's capital, Ottawa. Prior to commencing my dissertation research, I viewed a Canadian Broadcast Corporation film, The Disappearing Male (De Guerre, 2008), which featured citizens of Aamjiwnaang and their ongoing reproductive health concerns. The film drew attention to the community's recent discovery of a declining rate of male births, considered to be a result of noxious endocrine-disrupting chemicals released into the surrounding atmosphere (Mackenzie, Keith \& Lockridge, 2005). During my studies at the University of Ottawa, I began a Research Assistant position through York University's Faculty of Environmental Studies in Toronto, which sought to support the Aamjiwnaang First Nation Health and Environment Committee in its efforts to raise environmental awareness within the community, and to support youth efforts to defend their culture and land through creative modes of expression. During this experience, I worked alongside the faculty's research team on a PhotoVoice project that provided Aamjiwnaang youth 
with a lens through which they could shed light on their surroundings (Flicker, Savan, Kolenda \& Mildenberger, 2008; Scott \& Smith, 2012). In January 2011, following several conversations, ceremonial invitations, and established protocols, I relocated from Ottawa to the city of Sarnia, situated at the southernmost point of Lake Huron, Canada, on Aamjiwnaang land and next to Canada's 'Chemical Valley.'

In the final stages of my doctoral field research in 2011, at the request of then high school student Jacob Rogers (Jake), I began to work with youth leaders from the Young People's Council within Aamjiwnaang, as well as with an environmental youth group called the Aamjiwnaang Green Teens, on what came to be Indian Givers. Although my role as an informal advisor, consultant, and member of the research team was to examine how the community mobilized to seek recognition and redress for their ongoing health concerns, including a skewed birth ratio, as an academic-activist volunteer I supported youth activism within the community. Once my pre-determined phase of fieldwork and data collection came to a close in 2011, plans to leave Sarnia shifted when Jake approached me with a request to work together to disrupt misconceptions about Indigenous peoples in his local high school. We reached out to his peer leaders and together began to meet weekly, brainstorming a vision for how best to combat stereotypes and educate Western youth about Indigenous values and beliefs. So began our collective disruption.

Together, we discussed various issues that concerned these peer leaders, ranging from balancing their Indigenous identity with 'modern' society to protecting their increasingly polluted environment. Throughout the process, members of our newly formed Kiijig Collective - a name referring to "young people of the land" - began to find confidence in their voice (see Lindsay Gray, 15:00). In addition to giving visibility to the often invisible issue of racism, youth involved in the project were able to interview public figures in Sarnia, ask probing questions and document responses through the visual medium (see film scene with Sarnia Mayor Mike Bradley, 26:45). We chose filmmaking as the vehicle to advance intercultural dialogue for radical action and social change, because it offered a way for young people to raise their concerns with authority figures and address misinformation about Indigenous peoples, while collectively working toward decolonization.

\section{Co-Creating Knowledge: A Prismatic Process}

The key thing here is raising awareness. (Travis Stonefish, Nmaachihna Indigenous Enviro-Education Centre, Moraviantown, Indian Givers, 39:45)

Collaborative filmmaking unsettles, challenges, and ultimately seeks to change universal perspectives. It does so by refusing to gaze at an 'Other's' lived reality with curiosity, detachment, professionalism, and neutrality; 
instead, it aims to interrupt a monolithic gaze with the views of the participants themselves (Sontag, 1997, p. 55). In doing so, it moves beyond a voyeuristic, distanced, touristic, objective mode of looking at research subjects and instead looks alongside participants of a community. By bringing Indigenous and non-Indigenous youth together to work collectively, our Kiijig Collective attempted to create space for us to see and interpret injustice together. As a result, change occurred for both the youth who gained confidence in expressing their voices on screen and in terms of my own personal transformation as I learned about relational Indigenous values and beliefs. This informed our internal governance structure throughout the filmmaking process, and prompted us to move away from a hierarchical, linear research model of engagement.

As we came together, our group created a sense of community and a community of resistance. ${ }^{2}$ We sought to challenge dominant discourses "through group agency" (Shaw, 2012, p. 227). Evidenced by scenes in the film that show Indigenous youth in their everyday environments, this medium offers a glimpse into some of the ongoing challenges confronting the youth in their struggle for cultural survival. By working together, we hoped to raise awareness about the ongoing realities of Canadian colonization, including the persistent legacy of Residential Schools and the "60s Scoop" (Sucharov, 2015; Truth and Reconciliation Commission of Canada, 2015). As discussed in the film at 17:45, 24:00 and 25:20, both of these state-sanctioned policies entailed the mass removal of Indigenous children from their families by the Canadian child protection system.

Throughout our collaborative project, we continually revisited the Kiijig Collective's governance structure, roles, and responsibilities, as well as the overall message of the film. Such an iterative, rhizomatic, and non-linear communicative process signifies how film can function as a kind of prism for radical aesthetics and knowledge production (Deleuze \& Guattari, 1987; Lynes, 2013, p. 10). At the same time, we never entirely erased a hierarchical governance model. Early in our group's formation, we discussed and assigned respective roles and responsibilities. I was nominated the role of 'Executive Producer' given my position as a researcher familiar with how to leverage funding from various sources. During our discussions, we reviewed various duties associated with film production. Participating youth felt that given my presence in the community as a doctoral student and researcher, I would provide leadership as a liaison between Indigenous and non-Indigenous supporters. This role was crucial to securing funding from a range of sources

\footnotetext{
${ }^{2}$ Angela Davis used the term "community of resistance" in her remarks during the Wall Street Occupation in Washington Square Park, October 30, 2011 (see http://www.youtube.com/watch? v=HlvfPizooII; accessed December 17, 2013). Similar to questions posed by Davis (e.g., So how can we be together? How can we be together in a unity that respects and celebrates the differences among us?), the Kiijig Collective asked questions about how to work across differences to build a cultural understanding that is not simplistic or oppressive, but multifaceted, prismatic and complex.
} 
(including the Band's Education Department, Lambton-Kent School District, and the City of Sarnia), maintaining accountability to our funders (both Indigenous and non-Indigenous), and facilitating dialogue among all participating members of the Kiijig Collective.

Within a few months, we secured funds to finance pre-production, production, and post-production of the film. Most of our budget went to hiring local non-Indigenous filmmakers for each of these phases, as well as to costs associated with production, including gas, food, and accommodation for the crew to attend conferences and events as deemed necessary for the production process. As the only member of our production team with a vehicle, I often assumed the role of 'Line Producer' and ensured that group members had transportation to various shooting sites. We interviewed members of the Aamjiwnaaang First Nation, Elders, policy-makers and activists and wove together their stories with the broader narrative about the youth's struggle to reclaim their Indigenous identities, lands, and traditions. Production took place during an eight-month period in 2011-2012, followed by a series of iterative shooting/reviewing/editing meetings to discuss the overall scope and message of the film.

As noted above, our collective intended to make marginalized experience visible and knowable. In so doing, the film facilitated awareness about the community's "fleshy" and "situated knowledge" (Campbell, 2007, p. 379; Gabrielson \& Parady, 2010; Haraway, 1988, 1991; Mouffe, 2005; Yanow, 2003). Similar to other creative visual methodologies, filmmaking strives to create an atmosphere of engagement that is both emotional and transformative. The playful, collaborative filmmaking process can thus be an "affective vehicle" (Tremblay \& Jayme, 2015), which is experienced through the body (Bloustein, 2012, p. 121). During our interactions throughout the Indian Givers production process, for example, the ability to reflect back on oneself with a sense of humour, enabled by a relaxed and engaging atmosphere, provided space for ample learning moments. The resulting rapport allowed participating group members to enter some complex and difficult conversations about lived challenges pertaining to racism. As a relational, reciprocal, and affective tool, this approach made learning about difficult topics more inviting to young people who were brought into the process as co-learners and co-producers. In so doing, this process challenged existing societal power imbalances, while making knowledge accessible to communities beyond the academy.

As a group production, collaborations evoked deep connections among participants of the collective, thus disrupting conventional patterns of scholarly enterprise, which often operate under the guise of value-free, objective, and emotionless research. Throughout the filmmaking process, both Indigenous and Settler group members (including the hired filmmakers) confronted and reflected on their own positions, beliefs, and perspectives. At the same time, perfect reconciliation of diverse worldviews was not the objective of our project. Chantal Mouffe's notion of agonistic pluralism 
resonates; it questions unanimity and homogeneity while awarding a positive status to difference, highlighting how perfect reconciliation is an impossibility (2005, pp. 5, 9, 19, 98). For Mouffe, although deliberation may not always achieve consensus, deliberative tensions can be harnessed in productive ways to cultivate awareness.

The closing scenes of Indian Givers draw into focus the importance of agonistic pluralism in two ways. First, the action of Indigenous youth reclaiming their high school hallways while dressed in clothing traditional to their culture articulates their desire to make themselves visible and known, although their (predominantly) non-Indigenous peers demonstrated awe, dismay, or indifference. While no consensus was achieved between Indigenous and non-Indigenous peers, the film provides a forum for selfexpression without imposing one particular worldview on the viewer. Second, as Aamjiwnaang Elder Mike Plain articulates in the film's final frame, the mere existence of Indigenous peoples is an everyday act of survival and resistance. Although the film may not immediately lead to reconciliation between Indigenous and Western worldviews, it is a relational research tool that creates space for intercultural dialogue beyond the lifespan of the film, when used in a classroom setting to facilitate discussion. In this respect, academics teaching about topics pertaining to race and environmental justice can continue to be "together, apart" with community members while addressing common concerns in different contexts (Rancière, 2009, pp. 52, 57). As I discuss in greater detail below, by serving as a critical tool for social reflection and action, the film provided valuable lessons about intercultural encounters for both Indigenous and Settler collaborators.

\section{Learning from Community, Reaching Beyond the Academy}

Film, video art, photography, installation and all forms of art can rework the frame of our perceptions and the dynamism of our affects. As such, they can open up new passages towards new forms of political subjectivation. (Rancière, 2009, p.

Cultivating awareness about how all Canadians are implicated in ongoing processes of colonization is a first step toward addressing injustice. Doing so is not, however, a licence for researchers to speak for Indigenous peoples or to attempt single-handedly to solve apparent injustices without community consultation and input. Although "we must understand these relationships to understand ourselves and politics" (Shaw, 2008, p. 6), scholars attempting to decolonize engagement must be mindful of the danger in appropriating voice and assuming a leading role in organizing for justice (Tuhiwai Smith, 1999). As Donna Haraway (1991, p. 193) states, a researcher committed to social justice is obliged to respectfully join together with communities of difference "without claiming to be one another." Indeed, respect for difference does not 
entail erasing distinguishing features of one's identity; rather, a commitment to decolonization involves a willingness to open up the possibility for intercultural "engagement across difference" (Lynes, 2013, p. 20; Tuhiwai Smith, 1999).

Within our collective, this translated into facilitating dialogue and cocreating knowledge without fundamentally reconciling differences. However, while we learned from one another, we struggled to find a consensus on issues pertaining to funding, governance, ownership, and film distribution. We realized that developing a shared funding model that builds in a component for skills development amongst participants is crucial. To produce, shoot and edit the film, the Kiijig Collective hired Ian Alexander and Sadie Mallon, two independent Sarnia-based filmmakers from Western/European backgrounds. Although we applied for additional funding for capacity building and training for the Indigenous participants, we did not receive it. As a result, the filmmakers provided training on a volunteer basis by including the youth in all stages of the process. This is a limitation of the project. In order to be more thoroughly collaborative, participatory, and communitydriven, initiatives like this must develop skills and training among all participants and build them into the funding model from the outset.

We also struggled to find the most culturally appropriate governance model for our group and did not always reach a consensus about ownership of the footage gathered; moreover, some members were uncomfortable with entering the film into a festival circuit. The film certainly has the potential to contribute to meaningful discussion about Indigenous-Settler relations, environmental justice, and reconciliation, but our collective continues to debate the best process for translating the content into concrete policy outcomes. We agreed that it would be inappropriate to profit from the film, and decided to make the entire feature publicly accessible on YouTube, where it is available for use as a teaching tool for public education. As a courtesy, any member of the Kiijig Collective who screens the film lets the other members know. We determined that we all share responsibilities as equal spokespersons for the film.

From the outset, the collective agreed that the film would be a collaboratively produced product and not 'owned' by any member, and therefore came to an agreement that decision-making must be conducted collectively among the group by consensus. This was a challenge in the final stages, because not all participating youth could attend each post-production meeting. The final film was reviewed by all members and then screened at their high school in June, 2012. Additional screenings were subsequently held at several environmental justice conferences in Ontario, although not all youth had the support or funding to travel to these events. It is now clear to us that collaborative film initiatives must build in funding for dissemination.

At all stages of filmmaking, we sought advice and mentorship from the Education and Environment Departments in Aamjiwnaang, as well as from an Elder. Broadly speaking, the film proved to be well-received within the 
community, although a few of the youth involved in the project reported some strained relations in the immediate aftermath among their peers at school and with authority figures in the community. We addressed this issue in several sharing circles with our Elder advisor. This serves as a reminder that one cannot approach such processes with naiveté about the uncertainties, tensions, and frictions that inevitably emerge during creative collaborations. Power relations are always present in any democratic process, no matter how rational, reasonable, or consensus-based. Indeed, collaborative initiatives, like democratic deliberation, are "far from smooth" processes (Mouffe, 2005, p. 3). Nevertheless, power relations cannot simply be erased, and controversies and conflicts can be conduits for social change.

\section{Concluding Reflections on the Art of Engagement}

Grounded in relationships and informed by community engaged scholarship, collaborative filmmaking has much to offer the practice of academic-activist research that is oriented toward decolonization. As Indian Givers reveals, collaborative, community engaged processes can focus on diverse knowledges and experiences in order to shed light on the lived realities of those living with and 'sensing' the adverse effects of environmentally unjust public policies (Wiebe, forthcoming). By involving young people as conduits for translation, storytelling, and representation in their own words, terms, images, and emotions, film served as a compelling medium to "democratize experience" (Sontag, 1997, p. 3). For example, in the concluding scene of Indian Givers, the youth reclaimed their high school hallways wearing clothing traditional to their culture. These images served to "shock" viewers and offer them something different to see (Sontag, 1997, p. 19). By affecting the viewers and opening them up to seeing something anew, this emotional charge may prompt new thinking and novel insights.

Working toward social change in a contemporary context of ongoing colonization is no simple feat. Decolonization is a large challenge, requiring significant systematic and structural change. Co-creating knowledge about the lived effects of colonization is a starting point, and collaborative filmmaking is one small step toward the broader aim of decolonization. Scholars committed to addressing and interrupting injustices will need to think carefully about 'so what?' and 'what's next?' after provoking these artistic interventions. With respect to our collaboration in Aamjiwnaang, Indian Givers is, as noted, a publicly available film, which is now used in high school and university classrooms as a teaching tool. Going forward, to influence social change and support meaningful policy development, scholars and public officials must invest time and effort into relationship-building between community members, educators, and policy officials. Connecting experiential knowledge to policy-making processes requires both imagination 
and translation as academic-activists consider how best to inject this knowledge into systemic legal and policy processes.

As an academic-activist committed to the practice of community engaged scholarship, I continue to employ visual tools in ongoing research projects that work closely with Indigenous communities who seek to co-create knowledge by identifying problems, research approaches, and viable solutions together. For example, To Fish as Formerly is a short film I coproduced with members of the Tsawout First Nation on Vancouver Island (British Columbia), ${ }^{3}$ which the community screened as part of their Aboriginal oral evidence before a National Energy Board Hearing in Victoria on November 28 ${ }^{\text {th }}, 2014$ (NEB Hearing Order OH-001-2014: 11565). Through these types of creative, collaborative interventions between Indigenous and Settler communities, arts-based research can complement existing academic-activist scholarship by creating space for difference and dialogue.

Although these processes can create safe spaces and culturally appropriate contexts for knowledge sharing, as researchers entering and departing this terrain we must be mindful of our responsibilities to and relationships with the people and places encountered in our research. Mouffe's notion of agonistic pluralism accentuates how the task of democratic politics - and by extension democratic academic-activist research projects - must not "eliminate passions from the sphere of the public" (2005, p. 103). To be clear, the research process is not free from friction, but friction can also be productive for dialogue. Rather than erasing difference, dialogical initiatives informed by Mouffe's notion of radical democracy bring conflicts to the fore, "to make them visible so that they can enter the terrain of contestation" (2005, p. 34). Collaborative filmmaking as an anti-oppressive research tool is both radical and relational: it brings into focus opportunities for community building through site-specific struggles on an iterative, ongoing basis. At the same time, this prismatic process does not seek to erase difference but sheds light on dissenting voices, while making space for and facilitating the expression of diverse perspectives.

\section{Acknowledgments}

This research benefitted from a Social Sciences and Humanities Research Council of Canada (SSHRC)-funded Joseph-Armand Bombardier Canada Graduate Scholarship, an Ontario Graduate Scholarship (OGS), and a Population Health Improvement Research Network Award. I wish to express very special thanks to all members of the Aamjiwnaang Green Teens, Young People's Council Within Aamjiwnaang, and Kiijig Collective, for their continued openness and contributions to the production of Indian Givers.

\footnotetext{
${ }^{3}$ Access To Fish as Formerly at https://www.youtube.com/watch?v=vTQk1IR9ibc
} 
Funding from the Lambton-Kent School District, the City of Sarnia, and the Aamjiwnaang First Nation Education and Environment Departments made this film possible. This article benefitted from feedback during the Community Filmmaking \& Cultural Diversity conference at the British Film Institute in January 2014. I am also grateful to have benefitted from numerous conversations with affiliates of the Institute for Studies and Innovation in Community University Engagement at the University of Victoria who helped me craft these ideas. Comments and feedback from my dear friend, Boreal Collective photojournalist and constant creative source of inspiration Laurence Butet-Roch, significantly enhanced this paper. Finally, I would like to say thank you to the external reviewers and special issue editors for creating a productive space to flesh out academic-activist scholarship. This opportunity helped to sharply hone my contributions to the field, both in the community and in the academy.

\section{References}

Banister, E., Leadbeater, B., \& Marshall, A. (2011). Knowledge translation in context. Toronto: University of Toronto Press.

Bloustein, G. (2012). Play, affect, and participatory video as a reflexive research strategy. In E-J. Milne, C. Mitchell \& N. de Lange (Eds.), The handbook of participatory video (pp. 115130). Lanham: Altamira Press.

Bouchard, G, \& C. Taylor. (2008). Building the future: A time for reconciliation. (Report of the Consultation Commission on Accommodation Practices Related to Cultural Diversity). Quebec: Government of Quebec. Retrieved from https://www.mce.gouv.qc.ca/publications/CCPARDC/rapport-final-integral-en.pdf

Cahill, C. (2007). The personal is political: Developing new subjectivities in a participatory action research process. Gender, Place, and Culture, 14(3), 267-292.

Campbell, D. (2007). Geopolitics and visuality: Sighting the Darfur conflict. Political Geography, 26(1), 357-382.

Clover, D. (2011). Successes and challenges of feminist arts-based participatory methodologies with homeless/street-involved women in Victoria. Action Research, 9(12), 12-26.

Clover, D. (2014). Facilitating and teaching feminist visual arts-based research. In C. Etmanski, B. Hall \& T. Dawson (Eds.), Learning and teaching community-based research (pp. 135149). Toronto: University of Toronto Press.

De Guerre, M. (Writer \& Director), \& Mendelsohn, A. (Director). (2008). The Disappearing male. Canada: Canadian Broadcasting Corporation and Red Apple Entertainment.

Deleuze, G., \& Guattari, F. (1987). A thousand plateaus: Schizophrenia and capitalism. Minneapolis: University of Minnesota Press.

Ecojustice. (2007). Exposing Canada's Chemical Valley. Toronto: Ecojustice.

Flicker, S., Savan, B., Kolenda, B., \& Mildenberger, M. (2008). A snapshot of community-based research in Canada: Who? What? Why? How? Health Education Research, 23(1), 106-114.

Gabrielson T., \& Parady, K. (2010). Corporeal citizenship: Rethinking green citizenship through the body. Environmental Politics, 19(3), 374-391.

Hankivsky, O. (Ed.). (2012). An intersectionality-based policy analysis framework. Vancouver: BC Institute for Intersectionality Research and Policy, Simon Fraser University.

Haraway, D. (1988). Situated knowledges: The science question and the privilege of partial perspective. Feminist Studies, 14(3), 575-599.

Haraway, D. (1991). Simians, cyborgs, and women: The reinvention of nature. New York: Routledge. 
Hoover, E., Cook, K., Plain, R., Sanchez, K., Waghiyi, V., Miller, P., . . . Carpenter, D. (2012). Indigenous peoples of North America: Environmental exposures and reproductive justice. Environmental Health Perspectives, 120(12), 1645-1649.

Kindon, S. (2003). Participatory video in geographic research: A feminist practice of looking? Area, 35(2), 142-153.

Kovach, M. (2009). Indigenous methodologies: Characteristics, conversations, and contexts. Toronto: University of Toronto Press.

Lynes, K. (2013). Prismatic media, transnational circuits: Feminism in a globalized present. New York: Palgrave Macmillan.

Mackenzie, C., Keith, M., \& Lockridge, A. (2005). Declining sex ratio in a First Nations community. Environmental Health Perspectives, 113(10), 1295-1298.

Miller, E., \& Smith, M. (2012). Dissemination and ownership of knowledge. In E-J. Milne, C. Mitchell \& N. de Lange (Eds.), The handbook of participatory video (pp. 331-348). Lanham: Altamira Press.

Mouffe, C. (2005). The democratic paradox. London: Verso.

Mullin, A. (2003). Feminist art and the political imagination. Hypatia, 18(4), 190-213.

National Energy Board (NEB) (2014). .Hearing Order OH-001-2014. Trans mountain pipeline ULC: Trans mountain expansion project. Volume 23: November $28^{\text {th }} 2014$. Victoria, BC.

Nyers, P. (2010). No one is illegal between city and nation. Studies in Social Justice, 4(2), $127-$ 143.

Ochocka, J., \& Janzen, R. (2014). Breathing life into theory: Illustrations of community-based research, hallmarks, functions and phases. Gateways: International Journal of Community Research and Engagement, 7, 18-33.

Pain, R. (2004). Social geography: Participatory research. Progress in Human Geography, 25(8), 652-663.

Rancière, J. (2004). The politics of aesthetics. London: Bloomsbury.

Rancière, J. (2009). The emancipated spectator. London: Verso.

Scott, D., \& Smith, A. (2012). The green teens of Aamjiwnaang make the connection. Canadian Dimension, 6(1), 20.

Shaw, J. (2012). Interrogating the gap between the ideals and practice reality of participatory video. In E-J. Milne, C. Mitchell \& N. de Lange (Eds.), The handbook of participatory video (pp. 225-241). Lanham: Altamira Press.

Shaw, K. (2008). Indigeneity and political theory: Sovereignty and the limits of the political. London: Routledge.

Sontag, S. (1997). On photography. New York: Picador.

Sucharov, M. (2015, June 25). The 'Sixties Scoop' still ripples through Canadian families. The Globe and Mail. Retrieved from: http://www.trc.ca/websites/trcinstitution/index.php?p=4

Thomas, V., \& Britton, K. (2012). The art of participatory video: Relational aesthetics in artistic collaborations. In E-J. Milne, C. Mitchell \& N. de Lange (Eds.), The handbook of participatory video (pp. 208-222). Lanham: Altamira Press.

Tremblay, C., \&. Jayme, B. (2015). Community knowledge co-creation through participatory video. Action Research, 13(3), 298-314.

Truth and Reconciliation Commission of Canada (2015). TRC Final Report. Retrieved from: http://www.trc.ca/websites/trcinstitution/index.php?p=890

Tuhiwai Smith, L. (1999). Decolonizing methodologies: Research and indigenous peoples. London: Zed Books.

Wiebe, S., \& Konsmo, E. (2014). Indigenous body as contaminated site? Examining reproductive justice in Aamjiwnaang. In F. Scala, S. Paterson \& M. Sokolon (Eds.), Fertile ground: Exploring reproduction in Canada (pp. 325-358). Montreal \& Kingston: McGill-Queen's University.

Wiebe, S., \& Taylor, M. (2014). Pursuing excellence in collaborative community-campus research: 2014 CCCR national summit backgrounder. (Background paper prepared for the 2014 CCCR National Summit, November 3-4, 2014.) Community-Based Research Canada. Retrieved from:

http://www.communitybasedresearch.ca/resources/677\%20National\%20Summit/Participant \%20Backgrounder\%200ct\%2029.compressed.pdf 
Wiebe, S. (forthcoming). Everyday exposure: Indigenous mobilization and environmental justice in Canada's chemical valley. Vancouver: UBC Press.

Yanow, D. (2003). Assessing local knowledge. In H.M.A. Wagenar (Ed.), Deliberative policy analysis: Understanding governance in the network society (pp. 228-246). Cambridge: Cambridge University Press. 